\title{
Effects of microsatellite instability on recurrence patterns and outcomes in colorectal cancers
}

Chang Gon Kim¹, Joong Bae Ahn ${ }^{1}$, Minkyu Jung ${ }^{1}$, Seung Hoon Beom ${ }^{1}$, Chan Kim², Joo Hoon Kim ${ }^{1}$, Su Jin $\mathrm{Heo}^{1}$, Hyung Soon Park${ }^{1}$, Jee Hung Kim${ }^{1}$, Nam Kyu Kim³ ${ }^{3}$ Byung Soh Min ${ }^{3}$, Hoguen Kim ${ }^{4}$, Woong Sub Koom ${ }^{5}$ and Sang Joon Shin*,1

${ }^{1}$ Division of Medical Oncology, Department of Internal Medicine, Yonsei Cancer Center, 50 Yonsei-ro, Seodaemun-gu, Seoul 120-752, South Korea; 'Division of Medical Oncology, Department of Internal Medicine, CHA Bundang Medical Center, 59 Yatap-ro, Bundang-gu, Seongnam 463-712, South Korea; ${ }^{3}$ Department of Surgery, Yonsei Cancer Center, 50 Yonsei-ro, Seodaemun-gu, Seoul 120-752, Korea; ${ }^{4}$ Department of Pathology, Yonsei Cancer Center, 50 Yonsei-ro, Seodaemun-gu, Seoul 120-752, South Korea and ${ }^{5}$ Department of Radiation Oncology, Yonsei Cancer Center, 50 Yonsei-ro, Seodaemun-gu, Seoul 120-752, South Korea

Background: Among colorectal cancers (CRCs), high-frequency microsatellite instability (MSI-H) is associated with a better prognosis, compared with low-frequency MSI or microsatellite stability (MSI-L/MSS). However, it is unclear whether MSI affects the prognosis of recurrent CRCs.

Methods: This study included 2940 patients with stage I-III CRC who underwent complete resection. The associations of MSI status with recurrence patterns, disease-free survival (DFS), overall survival from diagnosis to death (OS1), and overall survival from recurrence to death (OS2) were analysed.

Results: A total of 261 patients (8.9\%) had MSI-H CRC. Patients with MSI-H CRC had better DFS, compared to patients with MSI-L/ MSS CRC (hazard ratio (HR): $0.619, P<0.001$ ). High-frequency microsatellite instability CRC was associated with more frequent local recurrence $(30.0 \%$ vs $12.0 \%, P=0.032)$ or peritoneal metastasis $(40.0 \%$ vs $12.3 \%, P=0.003)$, and less frequent lung $(10.0 \%$ vs $42.5 \%, P=0.004)$ or liver metastases (15.0\% vs 44.7\%, $P=0.01)$. Recurrent MSI-H CRC was associated with worse OS1 (HR: 1.363 , $P=0.035)$ and OS2 (HR: 2.667, $P<0.001)$. An analysis of patients with colon cancer yielded similar results.

Conclusions: Recurrence patterns differed between MSI-H CRC and MSI-L/MSS CRC, and recurrent MSI-H CRCs had a worse prognosis.

Colorectal cancers (CRCs) can be classified as cancers with microsatellite instability (MSI) and cancers with chromosomal instability but not MSI. Microsatellite instability occurs in $\sim 10-20 \%$ of CRCs, and results from deficient DNA mismatch repair (Koopman et al, 2009). It is further defined as the accumulation of errors in the DNA of microsatellite regions, and is caused by epigenetic inactivation of or germline mutations in mismatch repair genes, such as MLH1, MSH2, MSH6, and PMS2 (Poynter et al, 2008). CRCs with high-frequency MSI (MSI-H) frequently present in the right colon and are poorly differentiated, with mucinous features and marked lymphocytic infiltration (Kim et al, 1994).

Most previous studies have focused on the prognostic value of MSI in early-stage CRCs, which is generally associated with a good prognosis in patients with localised disease. This is presumably because of immunosurveillance and a relatively high rate of apoptosis (Michael-Robinson et al, 2001a, b; Benatti et al, 2005; Popat et al, 2005). However, CRCs with MSI-H have a worse

*Correspondence: Dr SJ Shin; E-mail: ssj338@yuhs.ac

Received 5 February 2016; revised 12 April 2016; accepted 6 May 2016; published online 26 May 2016

(c) 2016 Cancer Research UK. All rights reserved 0007-0920/16 
response to 5-fluorouracil (5-FU)-based chemotherapy, compared to CRCs with low-frequency microsatellite instability (MSI-L) or microsatellite stability (MSS), because of the reduced recognition of DNA adducts by the DNA mismatch repair system (Carethers et al, 1999; Ribic et al, 2003; Kim et al, 2007). Furthermore, because of their favourable prognosis, MSI-H CRC recurrence is rare. Although the recurrence patterns and outcomes have been briefly described in a few previous studies (Koopman et al, 2009; Sinicrope et al, 2011; Tran et al, 2011; Venderbosch et al, 2014), the prognostic value of MSI after recurrence is largely unknown. Therefore, in-depth investigations of the biological and clinical characteristics of recurrent MSI-H CRCs are warranted. In this study, we analysed the patterns and prognosis of recurrent CRCs in a large cohort of patients according to MSI status.

\section{PATIENTS AND METHODS}

Patients. This study evaluated 3326 patients who underwent complete resection (R0) for pathologically-confirmed stage I-III CRC at Yonsei Cancer Center between January 2002 and July 2013. However, 386 patients were excluded because of bowel obstruction at the initial presentation $(n=231)$, localised perforation $(n=123)$, synchronous cancer $(n=17)$, or confirmed metastatic lesions within 3 months after surgery $(n=15)$. Thus, 2940 patients were included in the analysis. The analysed data included patient demographics (age and sex), tumour characteristics (location, pathological stage, lymphovascular invasion, perineural invasion, number of retrieved lymph nodes, histological differentiation, and MSI status), and adjuvant chemotherapy regimen. The preoperative workup included a pathological tissue review, total colonoscopy, complete blood count, biochemical profiling, carcinoembryonic antigen (CEA) level measurement, and baseline chest and abdominopelvic computed tomography (CT). Staging was principally based on the guidelines for colon and rectal cancers in the seventh edition of the American Joint Committee on Cancer staging manual. This study was approved by the institutional review board of Yonsei Cancer Center.

MSI analysis. DNA was extracted from tumours and amplified using the PCR. High-frequency microsatellite instability was identified based on the presence of at least two of the five instability markers in the Bethesda microsatellite panel (BAT25, BAT26, MFD15, D2S123, and D5S346). Low-frequency microsatellite instability was identified based on the presence of only one instability marker, and MSS was identified based on the absence of instability markers. The MSI-L and MSS cases were grouped together (MSI-L/MSS) because no distinct differences between them were found in the previous studies (Laiho et al, 2002; Benatti et al, 2005; Popat et al, 2005).

Chemotherapy. No patients with stage I disease received adjuvant chemotherapy. Patients with stage II-III disease received adjuvant chemotherapy using either 5-FU/leucovorin or 5-FU/oxaliplatin/ leucovorin (FOLFOX), which was selected based on patient/ physician discussions. Adjuvant chemotherapy was recommended for patients with high-risk stage II tumours that were characterised by poor differentiation, lymphovascular or perineural invasion, $<12$ examined lymph nodes, or positive margins. FOLFOX was recommended for patients with stage III disease, except for patients in whom oxaliplatin was contraindicated because of old age, poor performance status, or pre-existing peripheral neuropathy.

Follow-up. Patients were followed up at 3-month intervals during the first 2 years after surgery, at 6-month intervals during the next 3 years, and annually thereafter. During the regular follow-ups, the serum CEA assay was performed at each visit. Abdominopelvic CT was performed at 6-month intervals, chest $\mathrm{CT}$ was performed at 12-month intervals, and both were performed annually after 5 years. If recurrence was suspected, then the follow-up examinations included clinical evaluation, physical examination, serum CEA assay, chest CT, abdominopelvic CT, colonoscopy, and positron emission tomography, as appropriate. Recurrence was determined using clinical and radiological examinations or histological assessment. Resectability of the metastatic disease at the time of recurrence or after conversion chemotherapy was evaluated by a multidisciplinary team.

Outcomes. Patterns of recurrence were determined according to the involved site and organ. Recurrence was categorised as local if it is occurred at or near the anastomosis site, or as systemic if it is occurred at a distant site. Disease-free survival (DFS) was defined as the time between the initial diagnosis and the first instance of disease recurrence or death. Overall survival (OS) was defined as the time between the initial diagnosis and death (OS1) or the time between recurrence and death (OS2).

Statistical analysis. Data were analysed using SPSS software (version 22.0; SPSS Inc., Chicago, IL, USA). Fisher's exact test and the Wilcoxon rank-sum test were used to examine the associations between MSI status and the clinicopathological variables. Survival plots were generated using the Kaplan-Meier method, and differences in the survival distributions were evaluated using the log-rank test. The Cox proportional hazards model was used to assess the effects of specified risk factors on survival. A $P$-value of $<0.05$ was considered as statistically significant.

\section{RESULTS}

Baseline characteristics, treatment variables, and outcomes among patients with CRC. Among the 2940 patients, 261 patients (8.9\%) had MSI-H CRC (Table 1). High-frequency microsatellite instability CRC was associated with a younger age, right colon location, early stage, less frequent lymphovascular invasion, more frequent evaluation of $\geqslant 12$ lymph nodes, and poor differentiation or a mucinous phenotype. Patients with MSI-H CRC were less likely to receive adjuvant chemotherapy, which was largely related to their earlier tumour stage. Patients whose tumours were less advanced, located in the colon, or categorised as MSI-H had a better DFS (Figure 1A-C). Patients with MSI-H CRCs had a better DFS, compared to patient with MSI-L/MSS CRCs, regardless of stage and location (Figure 1D-I). During a median follow-up of 61 months (range: 3-168 months), 394 patients (13.4\%) experienced recurrence. The incidences of overall recurrence $(14.0 \%$ vs $7.7 \%$, $P=0.004)$ and systemic recurrence $(13.1 \%$ vs $6.5 \%, P=0.002)$ were more frequent among patients with MSI-L/MSS CRCs, compared to patients with MSI-H CRCs.

Baseline characteristics, treatment variables, patterns of recurrence, and outcomes among patients with recurrent CRCs. Among the 394 patients who experienced recurrence, 20 patients (5.1\%) had MSI-H CRCs (Table 2). Similar to primary MSI-H CRCs, recurrent MSI-H CRCs were more common among young patients and in the right colon, and were usually poorly differentiated with a mucinous phenotype. When we compared patients with MSI-H or MSI-L/MSS CRC, we did not observe any significant differences in sex, tumour stage, presence of lymphovascular or perineural invasion, number of retrieved lymph nodes, and receipt of adjuvant chemotherapy.

The liver was the most common site of recurrence (170 patients), and was followed by the lungs (161 patients) and peritoneum (54 patients; Table 3). Patients with recurrent MSI-H CRC more frequently exhibited local recurrence $(30.0 \%$ vs $12.0 \%$, $P=0.032)$ and peritoneal metastases (40.0\% vs $12.3 \%, P=0.003)$, 
Table 1. Characteristics of patients with colorectal cancer according to microsatellite instability status

\begin{tabular}{|c|c|c|c|c|}
\hline & All patients $(n=2940)$ & MSI-H $(n=261)$ & MSI-L/MSS $(n=2679)$ & $P$-value \\
\hline \multicolumn{5}{|l|}{ Age, years } \\
\hline $\begin{array}{l}\text { Median } \\
\text { Range }\end{array}$ & $\begin{array}{c}63 \\
14-99\end{array}$ & $\begin{array}{c}57 \\
14-87\end{array}$ & $\begin{array}{c}63 \\
22-99\end{array}$ & $<0.001$ \\
\hline \multicolumn{5}{|l|}{ Sex } \\
\hline $\begin{array}{l}\text { Male } \\
\text { Female }\end{array}$ & $\begin{array}{l}1735(59.0 \%) \\
1205(41.0 \%)\end{array}$ & $\begin{array}{l}152(58.2 \%) \\
109(41.8 \%)\end{array}$ & $\begin{array}{l}1583(59.1 \%) \\
1096(40.9 \%)\end{array}$ & 0.792 \\
\hline \multicolumn{5}{|l|}{ Location } \\
\hline \multicolumn{5}{|l|}{ Stage } \\
\hline $\begin{array}{l}\text { I } \\
\text { II } \\
\text { III }\end{array}$ & $\begin{array}{r}553(18.8 \%) \\
1156(39.3 \%) \\
1231(41.9 \%)\end{array}$ & $\begin{array}{r}56(21.5 \%) \\
138(52.9 \%) \\
67(25.7 \%)\end{array}$ & $\begin{array}{r}497(18.6 \%) \\
1018(38.0 \%) \\
1164(43.4 \%)\end{array}$ & $<0.001$ \\
\hline $\begin{array}{l}\text { Yes } \\
\text { No }\end{array}$ & $\begin{array}{c}116(3.9 \%) \\
2824(96.1 \%)\end{array}$ & $\begin{array}{c}5(1.9 \%) \\
256(98.1 \%)\end{array}$ & $\begin{array}{c}111(4.1 \%) \\
2568(95.9 \%)\end{array}$ & 0.094 \\
\hline \multicolumn{5}{|l|}{ Retrieved lymph nodes } \\
\hline $\begin{array}{l}\geqslant 12 \\
<12\end{array}$ & $\begin{array}{r}2373(80.7 \%) \\
567(19.3 \%)\end{array}$ & $\begin{array}{c}245 \text { (93.9\%) } \\
16(6.1 \%)\end{array}$ & $\begin{array}{r}2128(79.4 \%) \\
551(20.6 \%)\end{array}$ & $<0.001$ \\
\hline \multicolumn{5}{|l|}{ Differentiation } \\
\hline $\begin{array}{l}\text { Well differentiated } \\
\text { Moderately differentiated } \\
\text { Poorly differentiated } \\
\text { Mucinous carcinoma }\end{array}$ & $\begin{array}{c}626(21.3 \%) \\
2130(72.4 \%) \\
121(4.1 \%) \\
63(2.1 \%)\end{array}$ & $\begin{aligned} 43(16.5 \%) \\
166(63.6 \%) \\
40(15.3 \%) \\
12(4.6 \%)\end{aligned}$ & $\begin{aligned} 583(21.8 \%) \\
1964(73.3 \%) \\
81(3.0 \%) \\
51(1.9 \%)\end{aligned}$ & $<0.001$ \\
\hline \multicolumn{5}{|c|}{ Adjuvant chemotherapy } \\
\hline
\end{tabular}

compared to patients with recurrent MSI-L/MSS CRCs. In addition, MSI-H CRCs more frequently recurred as isolated peritoneal $(25.0 \%$ vs $3.7 \%, P=0.001)$ or intra-abdominal lymphnode metastases $(15.0 \%$ vs $3.7 \%, P=0.048)$. In contrast, lung (42.5\% vs $10.0 \%, P=0.004)$ and liver metastases $(44.7 \%$ vs $15.0 \%$, $P=0.01)$ were more frequent among patients with MSI-L/MSS CRCs. Among the non-recurrent cases, better OS1 was associated with MSI-H CRC, compared with MSI-L/MSS CRC. In contrast, poorer OS1 and OS2 were associated with recurrent MSI-H CRC (Figure 1J-L). Patients with recurrent MSI-H CRC were less likely to undergo curative resection, compared to patients with recurrent MSI-L/MSS CRC (20.0\% vs 51.6\%, $P=0.01$; Table 4). Although the likelihood of curative resection at the initial recurrence was not different when we compared MSI-H and MSI-L/MSS CRCs $(20.0 \%$ vs $27.8 \%, P=0.609$ ), patients with MSI-H CRCs did not benefit from conversion chemotherapy. Thus, palliative chemotherapy without resection was a significantly more common treatment modality for recurrent MSI-H CRC, compared with MSI-L/MSS (75.0\% vs $44.1 \%, P=0.01)$.

Baseline characteristics, treatment variables, patterns of recurrence, and outcomes among patients with colon cancer. To exclude the anatomical effects of tumour location on the treatment variables and outcomes, we also analysed only the colon cancer cases by excluding 961 cases of rectal cancer. Among the 1979 patients with colon cancer, 227 patients (11.5\%) had MSI-H tumours (Supplementary Table 1). Similar to MSI-H CRCs, MSI-H colon tumours were associated with a younger age, right colon location, early stage, less frequent lymphovascular invasion, more frequent evaluation of $\geqslant 12$ lymph nodes, and poor differentiation or a mucinous phenotype. Compared to patients with MSI-L/MSS colon tumours, patients with MSI-H colon tumours were less likely to receive adjuvant chemotherapy. Although less advanced and MSI-H colon tumours were associated with better DFS, no difference in DFS was observed according to location (right vs left colon; Figure 2A-C). Patients with MSI-H tumours appeared to have a better DFS, compared to patients with MSI-L/MSS tumours, regardless of stage (Figure 2D-F).

During a median follow-up of 60 months (range: 3-168 months), 221 patients with colon cancer (11.2\%) experienced recurrence, who included 17 patients (17/227, 7.5\%) with MSI-H tumours and 204 patients $(204 / 1752,11.6 \%)$ with MSI-L/MSS tumours. Similar to their primary counterparts, recurrent MSI-H colon cancers were more frequently observed among young patients (Supplementary Table 2) and tended to recur locally (23.5\% vs $6.4 \%$ for MSI-H vs MSI-L/MSS, respectively; $P=0.031$; Supplementary Table 3). Compared to patients with recurrent MSI-L/MSS tumours, patients with MSI-H tumours more frequently experienced recurrence as peritoneal metastases (47.1\% vs $18.1 \%, P=0.009)$ and less frequently experienced recurrence as liver (17.6 vs $53.9 \%, P=0.005)$ or lung metastases (5.9\% vs $30.4 \%, P=0.046)$. Isolated peritoneal metastasis was more common in MSI-H tumours, compared with MSI-L/MSS tumours (29.4\% vs 6.4\%, $P=0.007)$. Among non-recurrent cases, better OS1 was associated with MSI-H tumours, compared with MSI-L/MSS tumours. In contrast, OS2 was worse for recurrent MSI-H tumours, although there was no significant difference in OS1 (Figure 2G-I). Similar to the recurrent CRC cohort, patients with 

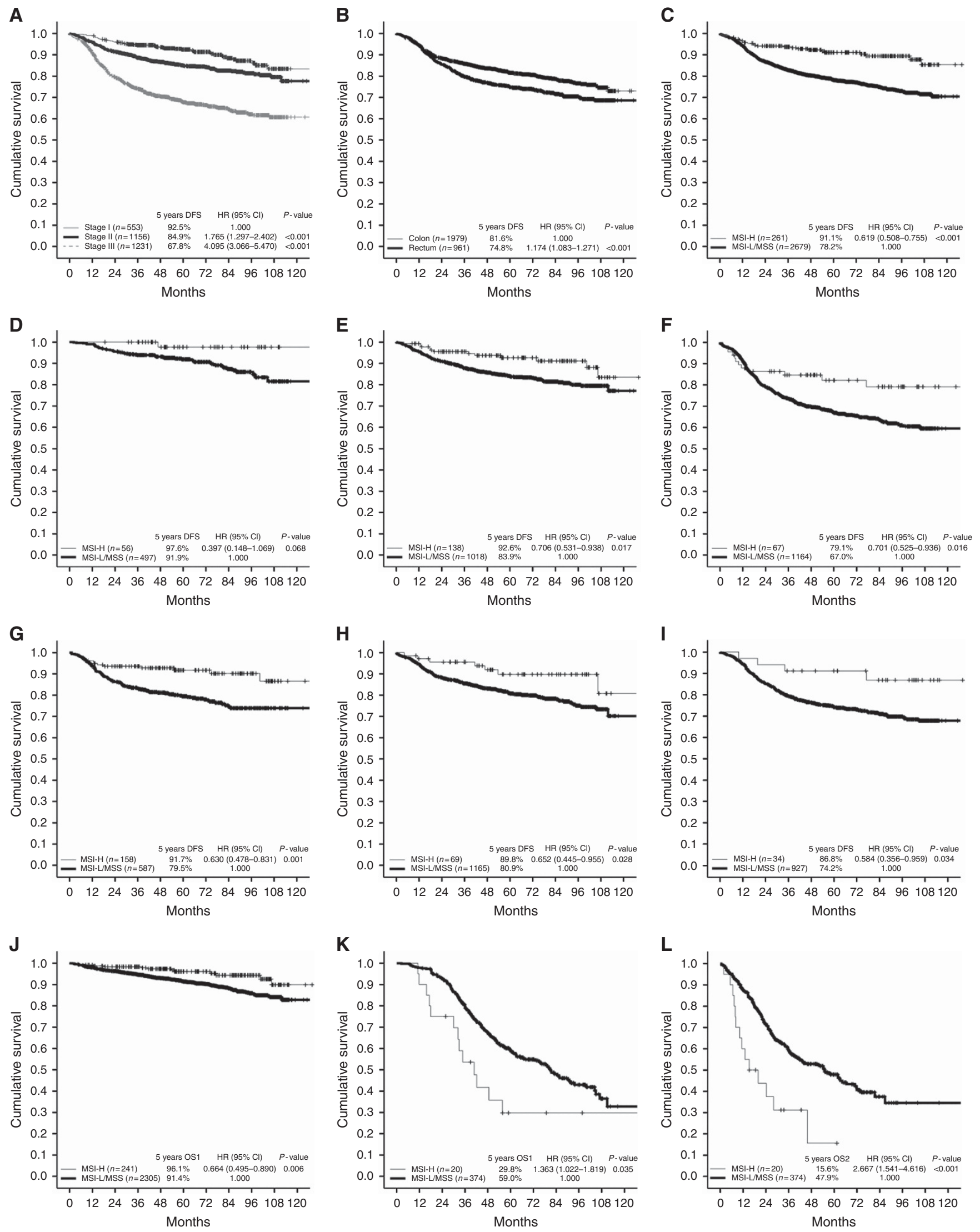

Figure 1. Kaplan-Meier analysis of survival among patients with colorectal cancer. Disease-free survival (DFS) according to stage (A), location (B), and microsatellite instability (MSI) status (C); DFS according to MSI status and stage (stages I-III in D-F, respectively) or location (right colon, left colon, and rectum in $\mathbf{G}, \mathbf{H}$, and $\mathbf{I}$, respectively). Overall survival from diagnosis to death (OS1) according to MSI status in patients without (J) and with recurrence $(\mathrm{K})$. Overall survival from recurrence to death (OS2) according to $\mathrm{MSI}$ status in patients with recurrence (L). Abbreviations: $\mathrm{Cl}$, confidence interval; HR, hazard ratio. 
Table 2. Characteristics of patients with recurrent colorectal cancer according to microsatellite instability status

\begin{tabular}{|c|c|c|c|c|}
\hline & All patients $(n=394)$ & MSI-H $(n=20)$ & MSI-L/MSS $(n=374)$ & $P$-value \\
\hline \multicolumn{5}{|l|}{ Age, years } \\
\hline $\begin{array}{l}\text { Median } \\
\text { Range }\end{array}$ & $\begin{array}{c}62 \\
14-86\end{array}$ & $\begin{array}{c}49 \\
14-72\end{array}$ & $\begin{array}{c}63 \\
28-86\end{array}$ & 0.001 \\
\hline \multicolumn{5}{|l|}{ Sex } \\
\hline $\begin{array}{l}\text { Male } \\
\text { Female }\end{array}$ & $\begin{array}{l}240(60.9 \%) \\
154(39.1 \%)\end{array}$ & $\begin{array}{r}13(65.0 \%) \\
7(35.0 \%)\end{array}$ & $\begin{array}{l}227(60.7 \%) \\
147(39.3 \%)\end{array}$ & 0.816 \\
\hline \multicolumn{5}{|l|}{ Location } \\
\hline \multicolumn{5}{|l|}{ Stage } \\
\hline $\begin{array}{l}\text { I } \\
\text { II } \\
\text { III }\end{array}$ & $\begin{array}{c}21(5.3 \%) \\
108(27.4 \%) \\
265(67.3 \%)\end{array}$ & $\begin{array}{c}1(5.0 \%) \\
5(25.0 \%) \\
14(70.0 \%)\end{array}$ & $\begin{array}{c}20(5.3 \%) \\
103(27.5 \%) \\
251(67.1 \%)\end{array}$ & 1 \\
\hline $\begin{array}{l}\text { Yes } \\
\text { No }\end{array}$ & $\begin{array}{c}32(8.1 \%) \\
362(91.9 \%)\end{array}$ & $\begin{array}{c}0(0.0 \%) \\
20(100.0 \%)\end{array}$ & $\begin{array}{c}32(8.6 \%) \\
342(91.4 \%)\end{array}$ & 0.391 \\
\hline \multicolumn{5}{|l|}{ Retrieved lymph nodes } \\
\hline $\begin{array}{l}\geqslant 12 \\
<12\end{array}$ & $\begin{array}{r}298(75.6 \%) \\
96(24.4 \%)\end{array}$ & $\begin{array}{r}17(85.0 \%) \\
3(15.0 \%)\end{array}$ & $\begin{array}{r}281(75.1 \%) \\
93(24.9 \%)\end{array}$ & 0.427 \\
\hline \multicolumn{5}{|l|}{ Differentiation } \\
\hline $\begin{array}{l}\text { Well differentiated } \\
\text { Moderately differentiated } \\
\text { Poorly differentiated } \\
\text { Mucinous carcinoma }\end{array}$ & $\begin{aligned} 64 & (16.2 \%) \\
296 & (75.1 \%) \\
20 & (5.1 \%) \\
14 & (3.6 \%)\end{aligned}$ & $\begin{array}{r}3(15.0 \%) \\
12(60.0 \%) \\
3(15.0 \%) \\
2(10.0 \%)\end{array}$ & $\begin{aligned} & 61(16.3 \%) \\
& 284(75.9 \%) \\
& 17(4.5 \%) \\
& 12(3.2 \%)\end{aligned}$ & 0.038 \\
\hline \multicolumn{5}{|l|}{ Adjuvant chemotherapy } \\
\hline
\end{tabular}

MSI-H colon cancer were less likely to undergo curative resection after recurrence $(17.6 \%$ vs $48.0 \%$ for MSI-H vs MSI-L/MSS, respectively; $P=0.021$; Supplementary Table 4). In addition, conversion chemotherapy was more successful for patients with MSI-L/MSS (22.1\% vs $0.0 \%$ for MSI-L/MSS vs MSI-H, respectively; $P=0.027$ ), and palliative chemotherapy without curative resection was the main therapeutic approach for patients with MSI-H $(76.5 \%$ vs $45.6 \%$ for MSI-H vs MSI-L/MSS, respectively; $P=0.021$ ).

\section{DISCUSSION}

The present study examined the effects of MSI on recurrence patterns and outcomes among patients with CRC. We found that MSI-H CRCs usually recurred locally, and that pulmonary and hepatic metastases were relatively uncommon. Although MSI-H was generally a good prognostic marker (higher DFS and OS1 rates), it was a poor prognostic marker in recurrent cases (lower OS1 and OS2 rates). Similar results were observed in our analysis of only colon cancers.

Approximately $10-20 \%$ of CRCs are diagnosed as MSI-H (Young et al, 2001; Giacomini et al, 2005). However, the reported prevalence varies according to ethnicity and the microsatellite markers that were used for the detection (Popat et al, 2005; Poynter et al, 2008). High-frequency microsatellite instability CRCs accounted for only $5.5 \%$ of CRCs among Korean patients and for 4.5-5.9\% of CRCs among Japanese patients (Asaka et al, 2009; Yamada et al, 2010; Oh et al, 2012). In the present study, which was conducted in Korea, $8.9 \%$ of the patients had MSI-H CRCs. These percentages are lower than those from Western countries and slightly higher than those from other Eastern countries. Similar to the previous studies, MSI-H CRC was associated with a younger age, proximal location, early stage, absence of lymphovascular invasion, a larger number of retrieved lymph nodes, and poor differentiation. In addition, patients with resected MSI-H CRCs had favourable outcomes, with fewer recurrences at distant sites (Benatti et al, 2005; Sinicrope et al, 2011; Klingbiel et al, 2015).

The different recurrence patterns that were observed in our study may be relevant to postoperative surveillance strategies. For example, local recurrences and peritoneal metastases were relatively common among patients with MSI-H CRCs. In addition, the peritoneum was the most common site of MSI-H CRC recurrence, whereas the liver and lungs were the most common sites of MSI-L/MSS CRC recurrence. Notably, extra-abdominal recurrence was infrequent among patients with MSI-H CRC, which agrees with the findings of a previous study (Sinicrope et al, 2011). Furthermore, lung metastases were observed in $<1 \%$ ( 2 out of 261) of patients with MSI-H CRCs during a median follow-up of 61 months, and in $<0.5 \%$ ( 1 out of 227) of patients with MSI-H colon cancers. The recently published follow-up guidelines endorsed by the National Comprehensive Cancer Network (Benson et al, 2014; Benson et al, 2015), the American Society of Clinical Oncology (Meyerhardt et al, 2013), and the European Society of Medical Oncology (Glimelius et al, 2013; van de Velde et al, 2014) recommend chest CT for patients who have undergone surgical resection for CRC. However, the low incidence of lung metastases among patients with MSI-H CRC or colon cancer may 
Table 3. Recurrence patterns in patients with colorectal cancer according to microsatellite instability status

\begin{tabular}{|c|c|c|c|c|}
\hline & All patients $(n=394)$ & MSI-H $(n=20)$ & MSI-L/MSS $(n=374)$ & $P$-value \\
\hline $\begin{array}{l}\text { Number of involved organs } \\
1 \\
2 \\
3 \text { or more }\end{array}$ & $\begin{array}{c}273(69.3 \%) \\
85(21.6 \%) \\
36(9.1 \%)\end{array}$ & $\begin{array}{c}15 \text { (75.0\%) } \\
4(20.0 \%) \\
1(5.0 \%)\end{array}$ & $\begin{array}{r}258 \text { (69.0\%) } \\
81(21.7 \%) \\
35(9.4 \%)\end{array}$ & 0.935 \\
\hline Local recurrence & $51(12.9 \%)$ & $6(30.0 \%)$ & $45(12.0 \%)$ & 0.032 \\
\hline $\begin{array}{l}\text { Systemic recurrence } \\
\text { Extra-abdominal recurrence } \\
\text { Lung } \\
\text { Extra-abdominal LN } \\
\text { Bone } \\
\text { Muscle } \\
\text { Brain } \\
\text { Intra-abdominal recurrence } \\
\text { Liver } \\
\text { Peritoneum } \\
\text { Intra-abdominal LN } \\
\text { Ovary } \\
\text { Ureter } \\
\text { Abdominal wall } \\
\text { Adrenal gland } \\
\text { Spleen } \\
\text { Pancreas }\end{array}$ & $\begin{aligned} & 368(93.4 \%) \\
& 180(45.7 \%) \\
& 161(40.9 \%) \\
& 19(4.8 \%) \\
& 14(3.6 \%) \\
& 4(1.0 \%) \\
& 1(0.3 \%) \\
& 256(65.0 \%) \\
& 170(43.1 \%) \\
& 54(13.7 \%) \\
& 48(12.2 \%) \\
& 17(4.3 \%) \\
& 7(1.8 \%) \\
& 6(1.5 \%) \\
& 3(0.8 \%) \\
& 2(0.5 \%) \\
& 1(0.3 \%)\end{aligned}$ & $\begin{aligned} 17(85.0 \%) \\
3(15.0 \%) \\
2(10.0 \%) \\
0(0.0 \%) \\
0(0.0 \%) \\
1(5.0 \%) \\
0(0.0 \%) \\
14(70.0 \%) \\
3(15.0 \%) \\
8(40.0 \%) \\
4(20.0 \%) \\
0(0.0 \%) \\
1(5.0 \%) \\
1(5.0 \%) \\
0(0.0 \%) \\
0(0.0 \%) \\
0(0.0 \%)\end{aligned}$ & $\begin{array}{c}351(93.9 \%) \\
177(47.3 \%) \\
159(42.5 \%) \\
19(5.1 \%) \\
14(3.7 \%) \\
3(0.8 \%) \\
1(0.3 \%) \\
242(64.7 \%) \\
167(44.7 \%) \\
46(12.3 \%) \\
44(12.8 \%) \\
17(4.5 \%) \\
6(1.6 \%) \\
5(1.3 \%) \\
3(0.8 \%) \\
2(0.5 \%) \\
1(0.3 \%)\end{array}$ & $\begin{array}{l}0.137 \\
0.005 \\
0.004 \\
0.613 \\
1 \\
0.189 \\
1 \\
0.811 \\
0.01 \\
0.003 \\
0.286 \\
1 \\
0.308 \\
0.27 \\
1 \\
1 \\
1\end{array}$ \\
\hline
\end{tabular}

Table 4. Treatment strategies after recurrence in patients with colorectal cancer according to microsatellite instability status

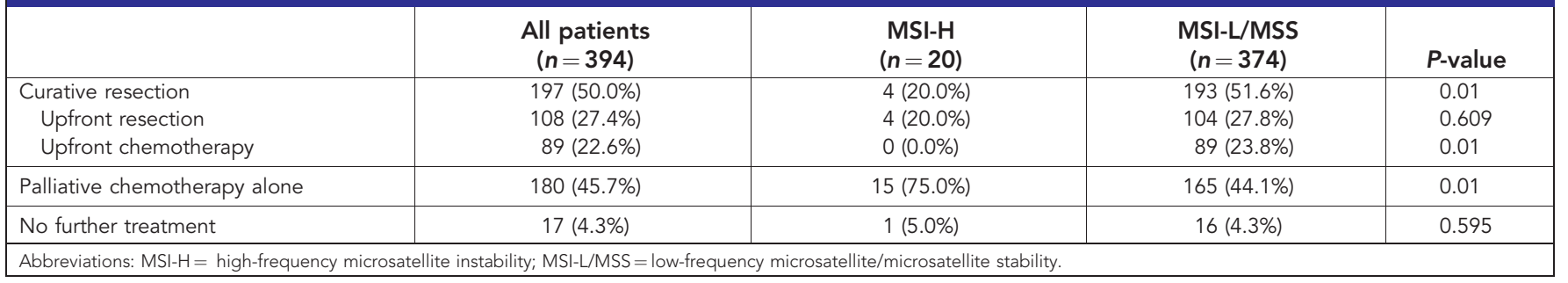

indicate that chest CT has limited clinical benefits in this population.

The recurrence pattern also affects the treatment strategy after recurrence. In our study, post-recurrence survival was worse among patients with MSI-H tumours, compared to patients with MSI-L/MSS tumours, and more than twice as many patients with MSI-L/MSS tumours experienced recurrent disease that was amenable to curative resection, compared to patients with MSI$\mathrm{H}$ tumours. Similarly, previous studies have revealed a decrease in the OS rate among patients with advanced MSI-H CRC. For example, the Dutch Colorectal Cancer Group performed the CAIRO study of 515 patients with stage IV diseases, and found a tendency towards inferior outcomes among patients with MSI-H CRC (Koopman et al, 2009). However, those authors were not able to draw definite conclusions regarding this trend, based on the small number of patients with MSI-H CRC. In a retrospective analysis that was conducted at the Royal Melbourne Hospital and University of Texas MD Anderson Cancer Center, MSI-H CRC was associated with poorer survival in cases of metastatic disease (Tran et al, 2011). That study also compared the patterns of metastatic spread and frequency of metastasectomy according to MSI status, and found higher rates of liver metastases and metastasectomy among patients with MSI-L/MSS CRC, which is similar to our findings. Moreover, a recently published pooled analysis of three prospective trials revealed that the poor prognosis of metastatic MSI-H CRCs appeared to be driven by BRAF mutations (Venderbosch et al, 2014).
There are two possible explanations for the worse outcomes among patients with recurrent MSI-H CRC. First, most patients with MSI-H tumours were not eligible for curative resection after recurrence. However, the surgical removal of oligometastases, especially liver and lung metastases, is generally considered as beneficial (Kanas et al, 2012; Salah et al, 2012), and metastasectomy can improve OS among patients with metastatic MSI-H CRCs (Goldstein et al, 2014). In addition, chemotherapeutic conversion to resectability was better among patients with MSI-L/MSS CRC, compared to patients with MSI-H CRC $(23.8 \%$ vs $0.0 \%, P=0.01)$, which reflects the intrinsic chemoresistance of MSI-H CRCs. Second, recurrent MSI-H tumours have developed mechanisms to overcome immunosurveillance. In early-stage MSI-H CRCs, tumour-specific neo-antigens induce strong local and systemic anti-tumour immune responses that correlate with a favourable prognosis (Buckowitz et al, 2005). Thus, the suppression or evasion of these responses is required for MSI-H CRC progression, which substantially increases the malignant potential, and the evolution of these immunoselective mechanisms has been associated with poor prognosis in several cancers (Seliger et al, 2002; Kloor et al, 2010). In recent studies, MSI-H tumours have been associated with expression of the immunosuppressive programmed death-1 receptor ligand (PD-L1) and sensitivity to PD-1 blockade (Rizvi et al, 2015; Schumacher and Schreiber, 2015). Similarly, a phase 2 study found that advanced MSI-H CRCs were more responsive to PD-1 blockade, compared with MSI-L/MSS CRCs (Le et al, 2015). Therefore, we expect that the inferior outcomes that are observed 
A

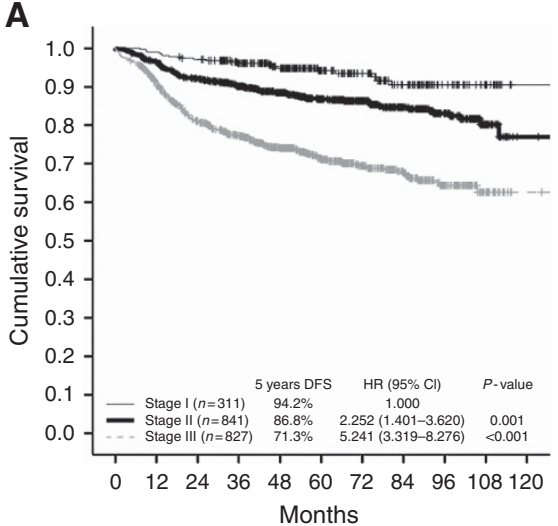

D

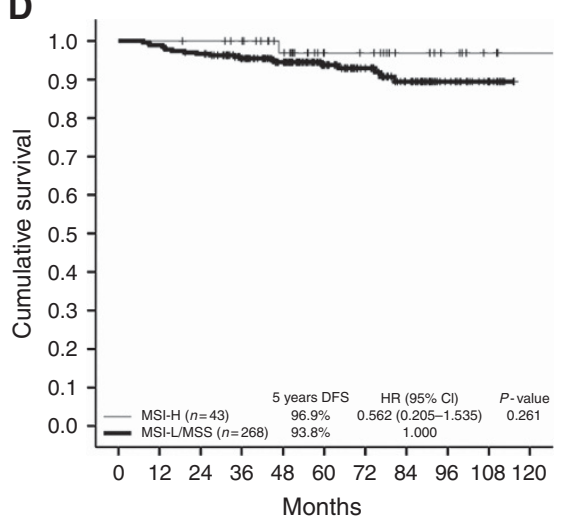

G

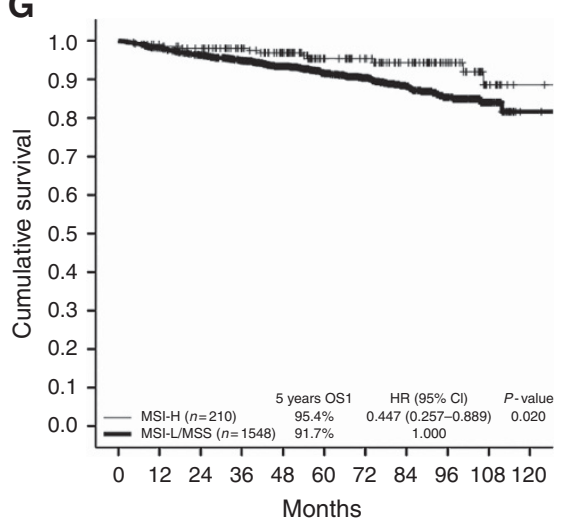

B

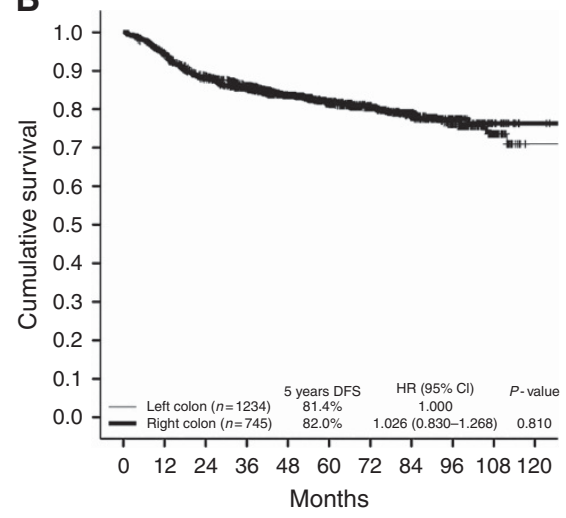

E

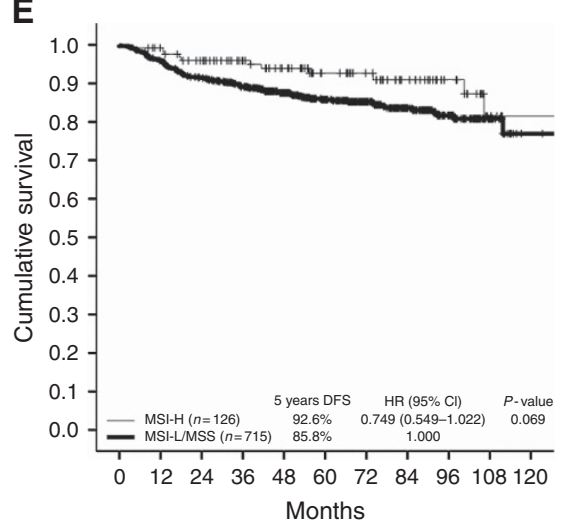

H

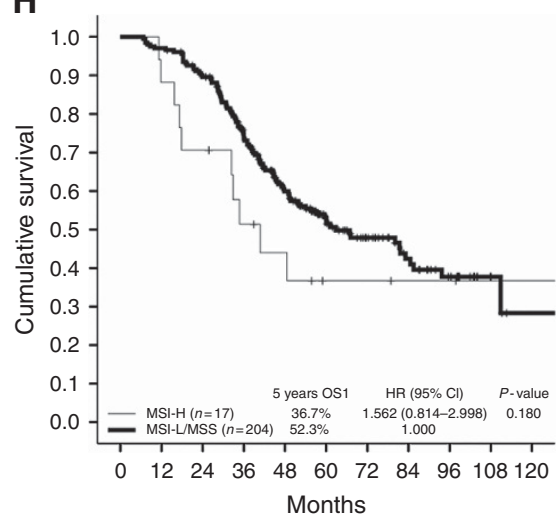

C

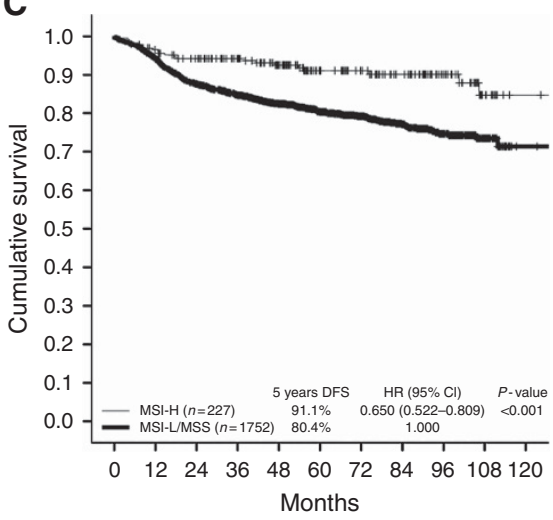

$\mathbf{F}$

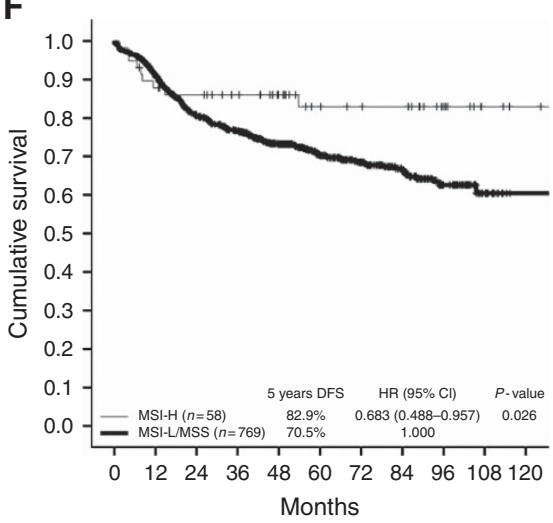

I

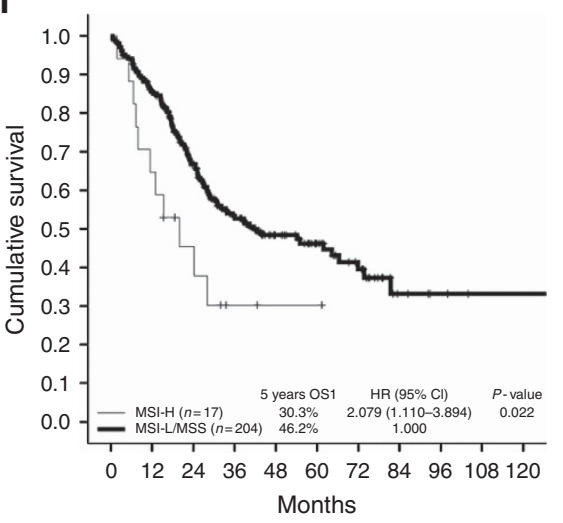

Figure 2. Kaplan-Meier analysis of survival among patients with colon cancer. Disease-free survival (DFS) according to stage (A), location (B), and microsatellite instability (MSI) status (C); DFS according to MSI status and stage (stages I-III in D-F, respectively). Overall survival from diagnosis to death (OS1) according to MSI status in patients without (G) and with recurrence $(\mathbf{H})$. Overall survival from recurrence to death (OS2) according to MSI status in patients with recurrence (I). Abbreviations: $\mathrm{Cl}$, confidence interval; HR, hazard ratio.

in patients with recurrent MSI-H CRCs could be overcome using immunotherapeutic approaches.

This study has two limitations. First, we did not fully evaluate the prognostic roles of $B R A F$ and germline mutations in $M L H 1$, $\mathrm{MSH} 2, \mathrm{MSH6}$, and PMS2, despite previous findings that MSI-H tumours with BRAF mutations or $M L H 1$ promoter methylation have a poor prognosis (French et al, 2008; Sinicrope et al, 2011). Previous studies have found an association between BRAF mutations and MSI-H through the high-level CpG island methylation phenotype (Dahlin et al, 2010; Lao and Grady, 2011; Tran et al, 2011; Venderbosch et al, 2014). In addition, $B R A F$ mutations are independently associated with increased recurrence and poor prognosis in resected CRC (Ogino et al, 2012; Schirripa et al, 2015; Seppala et al, 2015). However, the limited number of patients with known BRAF mutations in the present study precluded a more detailed molecular classification analysis. Second, this study was performed at a single centre, and the possibility of selection bias cannot be excluded. For example, curative resection was performed more frequently in the present study, especially after recurrence, compared with the previous studies (Pozzo et al, 2004; Alberts et al, 2005; Van Cutsem et al, 2006). Therefore, multicentre prospective studies are needed to further elucidate the characteristics of MSI-H CRC.

\section{CONCLUSION}

The present study identified different patterns of recurrence in patients with MSI-H CRC and MSI-L/MSS CRC. These findings 
suggest that modification of the current postoperative surveillance strategies should be considered. We also found an association between recurrent MSI-H CRC and a poor prognosis. Thus, investigation of the biological mechanisms and clinical implications of these findings will facilitate better patient counselling and provide an in-depth understanding of the MSI-H phenotype.

\section{ACKNOWLEDGEMENTS}

This work was supported by a grant from the National Research Foundation of Korea, which is administered by the Korean government (MSIP, 2015R1C1A1A01053547). We thank Dong-Su Jang for graphical assistance (a medical illustrator; Medical Research Support section, Yonsei University College of Medicine, Seoul, Korea), and Su Kyoung Park for data management assistance (Analysis Division of Medical Record Team, Yonsei Cancer Center, Seoul, Korea).

\section{CONFLICT OF INTEREST}

The authors declare no conflict of interest.

\section{REFERENCES}

Alberts SR, Horvath WL, Sternfeld WC, Goldberg RM, Mahoney MR, Dakhil SR, Levitt R, Rowland K, Nair S, Sargent DJ, Donohue JH (2005) Oxaliplatin, fluorouracil, and leucovorin for patients with unresectable liver-only metastases from colorectal cancer: a North Central Cancer Treatment Group phase II study. J Clin Oncol 23(36): 9243-9249.

Asaka S, Arai Y, Nishimura Y, Yamaguchi K, Ishikubo T, Yatsuoka T, Tanaka Y, Akagi K (2009) Microsatellite instability-low colorectal cancer acquires a KRAS mutation during the progression from Dukes' A to Dukes' B. Carcinogenesis 30(3): 494-499.

Benatti P, Gafa R, Barana D, Marino M, Scarselli A, Pedroni M, Maestri I, Guerzoni L, Roncucci L, Menigatti M, Roncari B, Maffei S, Rossi G, Ponti G, Santini A, Losi L, Di Gregorio C, Oliani C, Ponz de Leon M, Lanza G (2005) Microsatellite instability and colorectal cancer prognosis. Clin Cancer Res 11(23): 8332-8340.

Benson 3rd AB, Venook AP, Bekaii-Saab T, Chan E, Chen YJ, Cooper HS, Engstrom PF, Enzinger PC, Fenton MJ, Fuchs CS, Grem JL, Grothey A, Hochster HS, Hunt S, Kamel A, Kirilcuk N, Leong LA, Lin E, Messersmith WA, Mulcahy MF, Murphy JD, Nurkin S, Rohren E, Ryan DP, Saltz L, Sharma S, Shibata D, Skibber JM, Sofocleous CT, Stoffel EM, Stotsky-Himelfarb E, Willett CG, Gregory KM, Freedman-Cass D (2015) Rectal Cancer, Version 2.2015. J Natl Compr Cancer Netw 13(6): 719-728quiz 728.

Benson 3rd AB, Venook AP, Bekaii-Saab T, Chan E, Chen YJ, Cooper HS, Engstrom PF, Enzinger PC, Fenton MJ, Fuchs CS, Grem JL, Hunt S, Kamel A, Leong LA, Lin E, Messersmith W, Mulcahy MF, Murphy JD, Nurkin S, Rohren E, Ryan DP, Saltz L, Sharma S, Shibata D, Skibber JM, Sofocleous CT, Stoffel EM, Stotsky-Himelfarb E, Willett CG, Gregory KM, Freedman-Cass DA (2014) Colon cancer, version 3.2014. J Natl Compr Cancer Netw 12(7): 1028-1059.

Buckowitz A, Knaebel HP, Benner A, Blaker H, Gebert J, Kienle P, von Knebel Doeberitz M, Kloor M (2005) Microsatellite instability in colorectal cancer is associated with local lymphocyte infiltration and low frequency of distant metastases. Br J Cancer 92(9): 1746-1753.

Carethers JM, Chauhan DP, Fink D, Nebel S, Bresalier RS, Howell SB, Boland CR (1999) Mismatch repair proficiency and in vitro response to 5-fluorouracil. Gastroenterology 117(1): 123-131.

Dahlin AM, Palmqvist R, Henriksson ML, Jacobsson M, Eklof V, Rutegard J, Oberg A, Van Guelpen BR (2010) The role of the CpG island methylator phenotype in colorectal cancer prognosis depends on microsatellite instability screening status. Clin Cancer Res 16(6): 1845-1855.

French AJ, Sargent DJ, Burgart LJ, Foster NR, Kabat BF, Goldberg R, Shepherd L, Windschitl HE, Thibodeau SN (2008) Prognostic significance of defective mismatch repair and BRAF V600E in patients with colon cancer. Clin Cancer Res 14(11): 3408-3415.
Giacomini CP, Leung SY, Chen X, Yuen ST, Kim YH, Bair E, Pollack JR (2005) A gene expression signature of genetic instability in colon cancer. Cancer Res 65(20): 9200-9205.

Glimelius B, Tiret E, Cervantes A, Arnold D (2013) Rectal cancer: ESMO Clinical Practice Guidelines for diagnosis, treatment and follow-up. Ann Oncol 24(Suppl 6): vi81-vi88.

Goldstein J, Tran B, Ensor J, Gibbs P, Wong HL, Wong SF, Vilar E, Tie J, Broaddus R, Kopetz S, Desai J, Overman MJ (2014) Multicenter retrospective analysis of metastatic colorectal cancer (CRC) with high-level microsatellite instability (MSI-H). Ann Oncol 25(5): 1032-1038.

Kanas GP, Taylor A, Primrose JN, Langeberg WJ, Kelsh MA, Mowat FS, Alexander DD, Choti MA, Poston G (2012) Survival after liver resection in metastatic colorectal cancer: review and meta-analysis of prognostic factors. Clin Epidemiol 4: 283-301.

Kim GP, Colangelo LH, Wieand HS, Paik S, Kirsch IR, Wolmark N, Allegra CJ (2007) Prognostic and predictive roles of high-degree microsatellite instability in colon cancer: a National Cancer InstituteNational Surgical Adjuvant Breast and Bowel Project Collaborative Study. J Clin Oncol 25(7): 767-772.

Kim H, Jen J, Vogelstein B, Hamilton SR (1994) Clinical and pathological characteristics of sporadic colorectal carcinomas with DNA replication errors in microsatellite sequences. Am J Pathol 145(1): 148-156.

Klingbiel D, Saridaki Z, Roth AD, Bosman FT, Delorenzi M, Tejpar S (2015) Prognosis of stage II and III colon cancer treated with adjuvant 5-fluorouracil or FOLFIRI in relation to microsatellite status: results of the PETACC-3 trial. Ann Oncol 26(1): 126-132.

Kloor M, Michel S, von Knebel Doeberitz M (2010) Immune evasion of microsatellite unstable colorectal cancers. Int J Cancer 127(5): 1001-1010.

Koopman M, Kortman GA, Mekenkamp L, Ligtenberg MJ, Hoogerbrugge N, Antonini NF, Punt CJ, van Krieken JH (2009) Deficient mismatch repair system in patients with sporadic advanced colorectal cancer. Br J Cancer 100(2): 266-273.

Laiho P, Launonen V, Lahermo P, Esteller M, Guo M, Herman JG, Mecklin JP, Jarvinen H, Sistonen P, Kim KM, Shibata D, Houlston RS, Aaltonen LA (2002) Low-level microsatellite instability in most colorectal carcinomas. Cancer Res 62(4): 1166-1170.

Lao VV, Grady WM (2011) Epigenetics and colorectal cancer. Nat Rev Gastroenterol Hepatol 8(12): 686-700.

Le DT, Uram JN, Wang H, Bartlett BR, Kemberling H, Eyring AD, Skora AD, Luber BS, Azad NS, Laheru D, Biedrzycki B, Donehower RC, Zaheer A, Fisher GA, Crocenzi TS, Lee JJ, Duffy SM, Goldberg RM, de la Chapelle A, Koshiji M, Bhaijee F, Huebner T, Hruban RH, Wood LD, Cuka N, Pardoll DM, Papadopoulos N, Kinzler KW, Zhou S, Cornish TC, Taube JM, Anders RA, Eshleman JR, Vogelstein B, Diaz Jr. LA (2015) PD-1 blockade in tumors with mismatch-repair deficiency. $N$ Engl J Med 372(26): 2509-2520.

Meyerhardt JA, Mangu PB, Flynn PJ, Korde L, Loprinzi CL, Minsky BD, Petrelli NJ, Ryan K, Schrag DH, Wong SL, Benson 3rd AB (2013) Follow-up care, surveillance protocol, and secondary prevention measures for survivors of colorectal cancer: American Society of Clinical Oncology clinical practice guideline endorsement. J Clin Oncol 31(35): 4465-4470.

Michael-Robinson JM, Biemer-Huttmann A, Purdie DM, Walsh MD, Simms LA, Biden KG, Young JP, Leggett BA, Jass JR, Radford-Smith GL (2001a) Tumour infiltrating lymphocytes and apoptosis are independent features in colorectal cancer stratified according to microsatellite instability status. Gut 48(3): 360-366.

Michael-Robinson JM, Reid LE, Purdie DM, Biemer-Huttmann AE, Walsh MD, Pandeya N, Simms LA, Young JP, Leggett BA, Jass JR, Radford-Smith GL (2001b) Proliferation, apoptosis, and survival in high-level microsatellite instability sporadic colorectal cancer. Clin Cancer Res 7(8): 2347-2356.

Ogino S, Shima K, Meyerhardt JA, McCleary NJ, Ng K, Hollis D, Saltz LB, Mayer RJ, Schaefer P, Whittom R, Hantel A, Benson 3rd AB, Spiegelman D, Goldberg RM, Bertagnolli MM, Fuchs CS (2012) Predictive and prognostic roles of BRAF mutation in stage III colon cancer: results from intergroup trial CALGB 89803. Clin Cancer Res 18(3): 890-900.

Oh JR, Kim DW, Lee HS, Lee HE, Lee SM, Jang JH, Kang SB, Ku JL, Jeong SY, Park JG (2012) Microsatellite instability testing in Korean patients with colorectal cancer. Fam Cancer 11(3): 459-466.

Popat S, Hubner R, Houlston RS (2005) Systematic review of microsatellite instability and colorectal cancer prognosis. J Clin Oncol 23(3): 609-618.

Poynter JN, Siegmund KD, Weisenberger DJ, Long TI, Thibodeau SN, Lindor N, Young J, Jenkins MA, Hopper JL, Baron JA, Buchanan D, 
Casey G, Levine AJ, Le Marchand L, Gallinger S, Bapat B, Potter JD, Newcomb PA, Haile RW, Laird PW (2008) Molecular characterization of MSI-H colorectal cancer by MLHI promoter methylation, immunohistochemistry, and mismatch repair germline mutation screening. Cancer Epidemiol Biomarkers Prev 17(11): 3208-3215.

Pozzo C, Basso M, Cassano A, Quirino M, Schinzari G, Trigila N, Vellone M, Giuliante F, Nuzzo G, Barone C (2004) Neoadjuvant treatment of unresectable liver disease with irinotecan and 5-fluorouracil plus folinic acid in colorectal cancer patients. Ann Oncol 15(6): 933-939.

Ribic CM, Sargent DJ, Moore MJ, Thibodeau SN, French AJ, Goldberg RM, Hamilton SR, Laurent-Puig P, Gryfe R, Shepherd LE, Tu D, Redston M, Gallinger S (2003) Tumor microsatellite-instability status as a predictor of benefit from fluorouracil-based adjuvant chemotherapy for colon cancer. $N$ Engl J Med 349(3): 247-257.

Rizvi NA, Hellmann MD, Snyder A, Kvistborg P, Makarov V, Havel JJ, Lee W, Yuan J, Wong P, Ho TS, Miller ML, Rekhtman N, Moreira AL, Ibrahim F, Bruggeman C, Gasmi B, Zappasodi R, Maeda Y, Sander C, Garon EB, Merghoub T, Wolchok JD, Schumacher TN, Chan TA (2015) Cancer immunology. Mutational landscape determines sensitivity to PD-1 blockade in non-small cell lung cancer. Science (New York, NY) 348(6230): 124-128.

Salah S, Watanabe K, Welter S, Park JS, Park JW, Zabaleta J, Ardissone F, Kim J, Riquet M, Nojiri K, Gisabella M, Kim SY, Tanaka K, Al-Haj Ali B (2012) Colorectal cancer pulmonary oligometastases: pooled analysis and construction of a clinical lung metastasectomy prognostic model. Ann Oncol 23(10): 2649-2655.

Schirripa M, Bergamo F, Cremolini C, Casagrande M, Lonardi S, Aprile G, Yang D, Marmorino F, Pasquini G, Sensi E, Lupi C, De Maglio G, Borrelli N, Pizzolitto S, Fasola G, Bertorelle R, Rugge M, Fontanini G, Zagonel V, Loupakis F, Falcone A (2015) BRAF and RAS mutations as prognostic factors in metastatic colorectal cancer patients undergoing liver resection. Br J Cancer 112(12): 1921-1928.

Schumacher TN, Schreiber RD (2015) Neoantigens in cancer immunotherapy. Science (New York, NY) 348(6230): 69-74.

Seliger B, Cabrera T, Garrido F, Ferrone S (2002) HLA class I antigen abnormalities and immune escape by malignant cells. Semin Cancer Biol 12(1): 3-13.

Seppala TT, Bohm JP, Friman M, Lahtinen L, Vayrynen VM, Liipo TK, Ristimaki AP, Kairaluoma MV, Kellokumpu IH, Kuopio TH, Mecklin JP (2015) Combination of microsatellite instability and BRAF mutation status for subtyping colorectal cancer. Br J Cancer 112(12): 1966-1975.

Sinicrope FA, Foster NR, Thibodeau SN, Marsoni S, Monges G, Labianca R, Kim GP, Yothers G, Allegra C, Moore MJ, Gallinger S, Sargent DJ (2011)
DNA mismatch repair status and colon cancer recurrence and survival in clinical trials of 5-fluorouracil-based adjuvant therapy. J Natl Cancer Inst 103(11): 863-875.

Tran B, Kopetz S, Tie J, Gibbs P, Jiang ZQ, Lieu CH, Agarwal A, Maru DM, Sieber O, Desai J (2011) Impact of BRAF mutation and microsatellite instability on the pattern of metastatic spread and prognosis in metastatic colorectal cancer. Cancer 117(20): 4623-4632.

Van Cutsem E, Nordlinger B, Adam R, Kohne CH, Pozzo C, Poston G, Ychou M, Rougier P (2006) Towards a pan-European consensus on the treatment of patients with colorectal liver metastases. Eur J Cancer (Oxford, England: 1990) 42(14): 2212-2221.

van de Velde CJ, Boelens PG, Borras JM, Coebergh JW, Cervantes A, Blomqvist L, Beets-Tan RG, van den Broek CB, Brown G, Van Cutsem E, Espin E, Haustermans K, Glimelius B, Iversen LH, van Krieken JH, Marijnen CA, Henning G, Gore-Booth J, Meldolesi E, Mroczkowski P, Nagtegaal I, Naredi P, Ortiz H, Pahlman L, Quirke P, Rodel C, Roth A, Rutten H, Schmoll HJ, Smith JJ, Tanis PJ, Taylor C, Wibe A, Wiggers T, Gambacorta MA, Aristei C, Valentini V (2014) EURECCA colorectal: multidisciplinary management: European consensus conference colon \& rectum. Eur J Cancer (Oxford, England: 1990) 50(1): 1.e1-1.e34.

Venderbosch S, Nagtegaal ID, Maughan TS, Smith CG, Cheadle JP, Fisher D, Kaplan R, Quirke P, Seymour MT, Richman SD, Meijer GA, Ylstra B, Heideman DA, de Haan AF, Punt CJ, Koopman M (2014) Mismatch repair status and BRAF mutation status in metastatic colorectal cancer patients: a pooled analysis of the CAIRO, CAIRO2, COIN, and FOCUS studies. Clin Cancer Res 20(20): 5322-5330.

Yamada K, Kanazawa S, Koike J, Sugiyama H, Xu C, Funahashi K, Boland CR, Koi M, Hemmi H (2010) Microsatellite instability at tetranucleotide repeats in sporadic colorectal cancer in Japan. Oncol Rep 23(2): 551-561.

Young J, Simms LA, Biden KG, Wynter C, Whitehall V, Karamatic R, George J, Goldblatt J, Walpole I, Robin SA, Borten MM, Stitz R, Searle J, McKeone D, Fraser L, Purdie DR, Podger K, Price R, Buttenshaw R, Walsh MD, Barker M, Leggett BA, Jass JR (2001) Features of colorectal cancers with high-level microsatellite instability occurring in familial and sporadic settings: parallel pathways of tumorigenesis. Am J Pathol 159(6): 2107-2116.

This work is published under the standard license to publish agreement. After 12 months the work will become freely available and the license terms will switch to a Creative Commons AttributionNonCommercial-Share Alike 4.0 Unported License.

Supplementary Information accompanies this paper on British Journal of Cancer website (http://www.nature.com/bjc) 